V Congresso Brasileiro de Informática na Educação (CBIE 2016)

Anais do XXII Workshop de Informática na Escola (WIE 2016)

\title{
A linguagem dialógica no processo de produção textual escrita para curso a distância: composto significativo do material didático
}

\author{
Elaine Testoni ${ }^{1}$, Sílvia Dotta ${ }^{2}$ \\ ${ }^{1}$ Programa de Pós-Graduação em Ciências Humanas e Sociais - Universidade Federal do \\ ABC (UFABC) Avenida dos Estados, 5001 - CEP 09210-580 - Santo André - SP - Brasil \\ ${ }^{2}$ Centro de Matemática, Computação e Cognição - Universidade Federal do ABC (UFABC) \\ Avenida dos Estados, 5001 - CEP 09210-580 - Santo André - SP - Brasil \\ elaine.testoni@ufabc.edu.br, silvia.dotta@ufabc.edu.br
}

\begin{abstract}
This paper aims to present the dialogic text production process to distance course in which the object of analysis comprises the steps of textual constitution of a course directed at Basic Education. Thus, the linguistic resources will be explained which are based in dialogism as a way to promote interaction and the formation of discursive meanings. The expected results indicate the dialogic approaches as favorable recourse to acquisition of knowledge in the teaching-learning relationship
\end{abstract}

Resumo. O objetivo desse artigo é apresentar o processo de produção de texto dialógico escrito para curso a distância no qual o objeto de análise compreende as etapas de constituição textual de um curso voltado a professores do Ensino Básico. Desse modo, serão expressos os recursos linguísticos que se pautam no dialogismo como forma de promover a interação e a constituição dos sentidos discursivos. Os resultados esperados apontam as abordagens dialógicas como meio favorável à apreensão do conhecimento na relação ensino-aprendizagem.

\section{Introdução}

Os encadeamentos dialógicos presentes no processo de produção de textos que compõem e alicerçam o material didático para cursos a distância configuram práxis linguísticas centrípetas à edificação e apreensão do conhecimento. A linguagem dialógica empregada na constituição enunciativa dos discursos abrange diálogos sistematizados em uma relação de troca e de negociação de sentidos por parte dos interlocutores [Bakhtin, 2009].

O diálogo proveniente das abordagens bakhtinianas perpassa a denotação estrita da palavra visto que engloba a interação verbal e as significações provenientes de especificidades discursivas formam-se com base em outros elos enunciativos alicerçando o dialogismo. [Bakhtin, 2011]. Nas concepções de Freire [1987], o diálogo estabelecido na atividade educacional traduz a dicotomia do pensar e do agir aglutinada às mudanças socialmente constituídas que se fortalecem por meio de reações proativas e conscientes diante do mundo. 
V Congresso Brasileiro de Informática na Educação (CBIE 2016)

Anais do XXII Workshop de Informática na Escola (WIE 2016)

Nesse cenário, o fazer educativo amparado pela aprendizagem dialógica articula as correlações entre discursos a partir circunstâncias problematizadoras, críticas e nem sempre convergentes das quais as reflexões e obtenção de significados transformam pouco a pouco os saberes adquiridos [Dotta, 2011]. Assim sendo, a produção de textos pautada no dialogismo provoca inquietudes, fomenta motivações, ativa conexões tensas, incita recuperações discursivas e projeta situações futuras calcadas em novos discursos que integram combinações de interesses voltados à produção de sentido.

Desse modo, justificamos a escolha do tema apoiados no interesse de demonstrar a utilização da linguagem dialógica na arquitetura de textos produzidos para compor o material didático de um curso a distância. Isto posto, o objetivo desse estudo é explicitar a confecção textual cuja estrutura foi idealizada e edificada com base nas concepções do dialogismo de modo a oportunizar o favorecimento do ensino-aprendizagem na modalidade não presencial substanciada pela internet.

O problema tangencia as propriedades enunciativas de caráter sui-gêneris empregadas na composição do escopo dialógico que possam definir as abordagens contextuais como resultantes de uma linguagem harmônica e profícua à conveniência pedagógica. Logo, dispomos alguns questionamentos: quais atributos enunciativos contribuem para a configuração do dialogismo nos textos escritos? Como o emprego das propostas dialógicas beneficia a apreensão cognitiva?

As hipóteses são que os enunciados excedem as condições de produção respectivamente linguísticas e instituem variadas contextualizações nos diferentes teores enunciativos expressos em fenômenos socioculturais, históricos e ideológicos dos quais os sujeitos se inserem. Os discursos são tecidos em virtude das circunstâncias, da interação entre os atores comunicacionais, dos diálogos e nesse ínterim a linguagem multifacetada desvela contexturas interativas e dinâmicas abarcando situações problematizantes, ofertas de incentivo, convite ao pensamento crítico e reflexivo assim como a condução conversacional dos enunciados-verbais. Consequentemente, os benefícios das apropriações dialógicas são percebidos na aprendizagem colaborativa e no encontro da significação de significados que reunidos descortinam novos saberes e edificam a valorização do processo cognitivo.

O enfoque metodológico abarca a pesquisa exploratória na qual o objeto de investigação compreende uma experiência com o processo de produção de textos dialógicos para um curso a distância. Depreendemos para tanto, análises teóricas fundamentadas, entre outras possibilidades, nos estudos desenvolvidos por Bakhtin (2009, 2010, 2011), Freire $(1987,1996)$ e Dotta $(2009,2011)$.

Os pressupostos tratados neste artigo contemplam as tessituras dialógicas empregadas na produção de textos para um curso a distância com vistas ao favorecimento do material didático online sob uma perspectiva interacional de apreensão significativa do conhecimento no processo de ensino-aprendizagem.

\section{O dialogismo e as configurações enunciativas da linguagem}


V Congresso Brasileiro de Informática na Educação (CBIE 2016)

Anais do XXII Workshop de Informática na Escola (WIE 2016)

O dialogismo é parte constitutiva da linguagem e a condição do sentido discursivo em que o enunciador, para compor um discurso, atravessa o discurso de outrem e compartilha com ele uma interação dinâmica e tensa [Bakhtin, 2009]. A postura dialógica estabelece a condição interdiscursiva da linguagem e instaura uma permuta conversacional ora proveniente da troca entre o $e u$ e o tu no processo de comunicação interativa, ora do conflito oriundo da tensão básica na qual o tu determina o que o eu diz. Para tanto, a relação enunciativa com o sujeito determina um eu e consequentemente um $t u$ inserindo uma marca de pessoalidade independentemente do nível de participação que um concede ao outro no panorama discursivo [Brandão, 2004]. O discurso não compõe marca individual, ocorre na relação com o discurso alheio e aponta, de maneira implícita ou explícita, as marcas da heterogeneidade dispostas em instâncias sociais.

Orlandi (2008) atribui ao sujeito três enfoques: o primeiro aponta o processo de interlocução centrado na alteridade entre os participantes do discurso que exercem a interação entre o $e u$ e o $t u$. O segundo representa a divergência em relação ao outro na qual o $t u$ estabelece o que o eu diz. O terceiro configura o sujeito com traços dissonantes, inacabados aspirando pela sua completude. Nesse cenário, na correspondência entre identidade e alteridade o cerne da relação entre ambos não se encontra no eu tampouco no $t u$, mas no universo discursivo produzido entre este e aquele evidenciando, portanto que "o sujeito só se completa na interação com o outro" [Brandão, 2004, p. 54-55].

A interação entre os sujeitos discursivos no espaço comunicacional fornece subsídios necessários para que o enunciado se torne consistente ao relacionar-se com os outros e cria um amálgama de valores sintáticos e semânticos na projeção do diálogo. Em cada enunciado é possível depreender intenções, interpretar sentidos e avaliar posturas de ordem social e ideológica impressas nas verbalizações dos sujeitos que conduzem os esboços tangíveis no discurso [Bakhtin, 2011].

Foucault (2014) define o discurso como uma relação de enunciados reportada a uma mesma formação discursiva, isto é, um composto de enunciados com princípios de regularidade proveniente dos enunciados que o tece. Por meio do discurso é possível instaurar práticas discursivas de natureza heterogênea: imagem, som, letra e por isso é uma articulação constante configurada por ações simbólicas.

Para tanto, o discurso não é perpassado pela unidade do sujeito, mas pela dispersão correspondente às diversas maneiras possíveis de serem admitidas por ele no espaço discursivo, assim pode assumir diferentes vozes e apropriar-se de várias posições enunciativas [Foulcault, 2014].

Na co-relação com o outro, o sujeito adquire diversos papéis descortinando vozes formadoras de variados textos articulados no espaço e no tempo. As vozes são apreendidas a partir da realidade na qual os sujeitos estão imersos social e discursivamente, logo, à medida que tal realidade configura-se díspar, ocorre a absorção não de apenas uma, mas de várias vozes [Bakhtin, 2010]. Por esse prisma, a constituição dos enunciados pelos sujeitos reflete posturas ideológicas resultantes da internalização heterogênea destas vozes sociais e atuantes. 
V Congresso Brasileiro de Informática na Educação (CBIE 2016)

Anais do XXII Workshop de Informática na Escola (WIE 2016)

Nas relações dialógicas são caracterizadas as posturas do emissor e do receptor no processo comunicacional. O emissor utiliza a língua para apropriar-se das formas normativas e projetar os efeitos de sentido que permitem uma nova significação contextual. $\mathrm{O}$ receptor, por sua vez, busca apoderar-se de registros linguísticos para tornar o sentido textual pertinente às condições de uma dada circunstância. Instaura-se a descodificação dos signos com o intuito de identificar e compreender efeitos da linguagem [Dotta, 2009].

De acordo com Bakhtin (2009), a concepção ideológica está relacionada a signo e por sua vez compreende um significado exterior a si mesmo. Os signos são derivados de uma correspondência entre indivíduos e suas interações em sociedade, assim estabelecemse tanto pela organização social dos indivíduos quanto pelas circunstâncias do processo de interação. Como fenômeno de interação, ao enunciar o indivíduo cumpre o papel de sujeito ativo na composição dos sentidos e a linguagem veicula as articulações linguísticas, sociais e ideológicas.

Um signo não existe apenas como parte de uma realidade; ele também reflete e refrata uma outra. Ele pode distorcer essa realidade, ser-lhe fiel, ou apreendê-la de um ponto de vista específico, etc. Todo signo está sujeito aos critérios de avaliação ideológica. O domínio ideológico coincide com o domínio dos signos: são mutuamente correspondentes. Ali onde o signo se encontra, encontra-se também o ideológico [Bakhtin, 2009, p. 32].

A materialização sígnica ocorre na comunicação, lugar em que a interação verbal evidencia a linguagem como campo privilegiado da materialização ideológica [Bakhtin, 2009]. O ambiente social nutre as reflexões ideológicas e na inter-relação cotidiana, os signos ideológicos modificam-se e são modificados a partir da composição ativa e interacional.

\section{Metodologia}

O mecanismo de análise, objeto desse estudo, refere-se a uma experiência voltada ao processo de produção de textos dialógicos escritos os quais compreendem o material didático desenvolvido para um curso de extensão universitária a distância, oferecido pela Universidade Federal do ABC, em 2016. Esse curso denomina-se Antártica ou Antártida? Como inserir as Ciências Polares no currículo do Ensino Básico? e é dirigido a professores da Educação Básica com o propósito de torná-los multiplicadores das Ciências Antárticas no cenário educacional. Os materiais ofertados abordam temas introdutórios e diversos sobre o Continente Antártico cuja produção textual dialógica "traduz" a linguagem científica para uma linguagem acessível à sala de aula.

O curso dispõe uma carga de 60 horas/aula, está dividido em seis módulos independentes (Bússola, Destino, Vida, Gelo, Ambiente e Convergência) e possui duração em doze semanas. Sua estrutura alicerça-se em um tripé sistematizado por meio de recursos materiais (videoaulas, textos, tutoriais), "Atividades" (fórum, projeto, rede social) e "Comunicação" (apoio pedagógico, apoio técnico e fórum de grupo) no qual os princípios atendem a uma perspectiva dialógica e problematizadora responsável pela contínua interação entre os interlocutores e os demais discursos oferecidos. 
As estruturas dialógicas dos enunciados que sustentam a produção dos textos escritos tangenciam as abordagens discursivas e as concepções verbais da linguagem admitindo delineamentos possíveis de serem percebidos em toda arquitetura contextual. Desse modo, tendo em vista a redação dialógica como parte expressiva do todo ofertado, faremos um recorte de algumas projeções textuais a fim de evidenciar a ocorrência do dialogismo no processo de produção e de forma gradativa, apontar as contribuições desse recurso linguístico à apreensão cognitiva.

Na essência desse propósito, o dialogismo articulado nos discursos nutre a interação entre os atores sociais, fomenta o diálogo, instiga a autonomia, estimula a reflexão em detrimento às respostas prontas, potencializa a linguagem conversacional e nas ações conjuntas dispostas para a educação a distância, fortalece a aprendizagem.

\section{Traços dialógicos no entrelaçamento discursivo das projeções textuais escritas}

O aparato linguístico partícipe da interação verbal revela-se aos locutores discursivos na conjuntura das enunciações voltadas a uma esfera ideológica vivenciada, por sua vez os discursos transpassam a dimensão das palavras que ouvimos ou proferimos e estão carregados de sentidos expressos em convenções distintas como verdades ou inverdades, significâncias ou insignificâncias, simpatias ou antipatias, importâncias ou trivialidades, afinidades ou disparidades, concordâncias ou discordâncias [Bakhtin, 2011].

À vista disso, em ambiente virtual de aprendizagem, a interação discursiva está aglutinada à escolha criteriosa de palavras que ao serem enunciadas possam favorecer um diálogo motivador com vistas à aproximação comunicativa dos interlocutores, à promoção de estímulos, bem como ao estabelecimento de parcerias sustentadas por uma propositura dialógica [Dotta, 2009]. "É assim que compreendemos as palavras e somente reagimos àquelas que despertam em nós ressonâncias ideológicas ou concernentes à vida" [Bakhtin, 2011, p. 99].

Por conseguinte, apresentamos na figura 1 a composição enunciativa da página inicial do curso a fim de demonstrar a escolha cautelosa das "palavras" utilizadas.

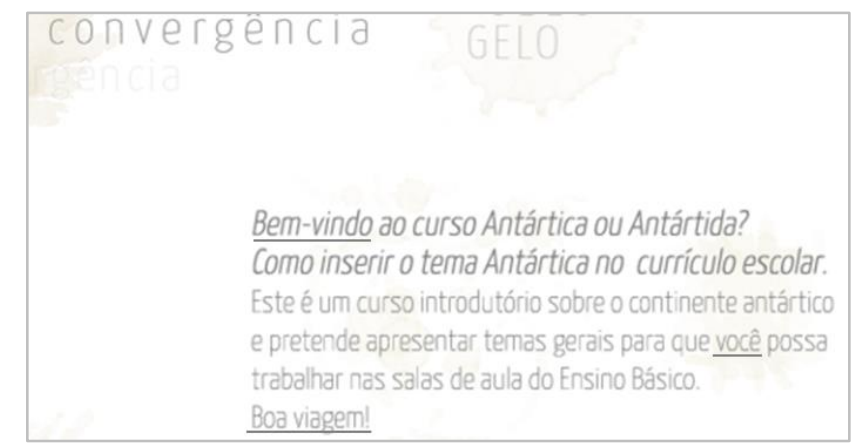

Figura 1. Delineamento enunciativo da página inicial

Observamos que as palavras "Bem-vindo", "você" e "Boa viagem", não são escolhidas aleatoriamente, assim quando instituídas em um contexto passam a compor um quadro discursivo que sinaliza uma ocorrência de significações. Essa condução dialógica 
V Congresso Brasileiro de Informática na Educação (CBIE 2016)

Anais do XXII Workshop de Informática na Escola (WIE 2016)

incentiva o diálogo, faculta o estreitamento de distâncias e expressa uma postura acolhedora e convidativa às descobertas que estão por vir.

Em outra perspectiva, os textos que compõem os módulos "Bússola" e "Destino" foram produzidos para orientar o cursista sobre as informações gerais do curso e portanto, nos apoiamos na proposta freireana de que ao promover a comunicação, o sujeito descobrese como parte do mundo e dele participa ativamente expandindo a sua capacidade de apreender conhecimentos [Freire, 1987]. A cognição não se encontra nem no sujeito e nem no objeto e ao agir sobre o objeto, o sujeito promove relações validando a aprendizagem sob perspectivas de âmbito social e cultural [Mello e Teixeira, 2011].

A produção enunciativa dos módulos "Vida", "Gelo", "Convergência" e "Ambiente" abarca conteúdos científicos sobre o continente branco e por esse motivo, recorremos a pesquisadores a fim de assegurar a veracidade dos conceitos "traduzidos" e reproduzidos para uma linguagem escrita de fácil compreensão. As características dialógicas empregadas nos quatro módulos disseminam vestígios interacionais, reiterando as concepções de Dotta (2009) de que os discursos refletem a presença de uma memória comum vivenciada entre os participantes.

A fim de explicitar as práxis dialógicas aplicadas na confecção dos textos de cada módulo, escolhemos algumas constituições enunciativas cujos recortes contextuais permitem beneficiar a compreensão dos procedimentos empregados. A figura 2 remete ao módulo "Vida" e exprime uma das várias abordagens discursivas alicerçadas no dialogismo.

Entre os maiores predadores dos mares antárticos está a foca-leopardo. Esta tem cabeça afilada, pode atingir cerca de 4 metros de comprimento e 500 quilos. Sua refeição favorita são os pinguins e também outras focas. $\underline{E}$, falando nela, o que você acha de descobrir um pouco mais sobre o estilo de vida desse animal? Esta é uma oportunidade para visualizar cenas incríveis que somente a natureza é capaz de oferecer. (Nosso grifo)

O vídeo Focas-leopardo, produzido pela NHNZ para a Animal Planet, demonstra as aventuras de um cinegrafista sueco nos mares da Antártica em uma experiência de tirar o fôlego. Com a intenção de registrar as focas-leopardo alimentando-se de pinguins-antárticos, ele teve de vencer o pavor de ficar frente a frente com uma. Assista e descubra as surpreendentes imagens que a câmera submarina pode registrar.

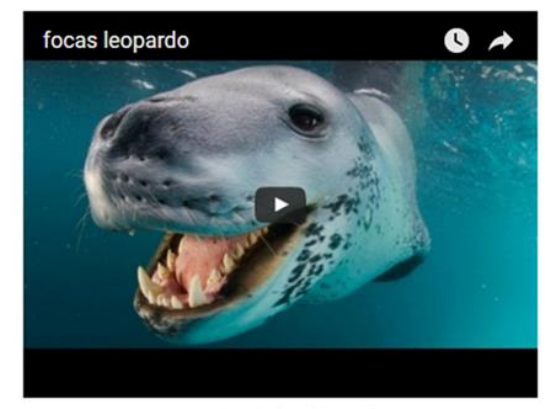

Figura 2. Módulo Vida - Mamíferos 
No primeiro parágrafo da figura 2, o discurso sublinhado manifesta uma textura dialógica na qual a produção enunciativa mescla-se à assimilação de conteúdo a partir da correspondência interlocutiva dos sujeitos sociais para a obtenção de significações. A expressividade das palavras no conjunto do enunciado permite fomentar posturas responsivas e reflexivas doravante circunstâncias problematizadoras ocasionadas pelo desempenho atitudinal do outro [Dotta e Testoni, 2015].

No segundo parágrafo, o amálgama das linguagens verbal e hipertextual seguido, $a$ posteriori de um vídeo, faculta-nos conduzir os interlocutores a explorar o pensamento crítico na busca das relações de sentidos estabelecidas entre as diferentes linguagens. Esse contexto reforça o princípio constitutivo do dialogismo de que "o enunciador, para constituir um discurso, leva em conta o discurso de outrem, que está presente no seu" [Fiorin, 2008, p. 19].

A figura 3 é diretiva à combinação de enunciados e esculpe outra convenção dialógica.

A Antártica não cessa em nos surpreender com a sua arquitetura e design gélidos. Você consegue imaginar uma cachoeira no visual antártico? Mas não estamos falando de uma cachoeira comum.

A região dos Vales Secos de McMurdo, que abriga, dentre outros, o Lago Vida e o Rio Onyx, também é morada de uma cascata de aproximadamente cinco andares de altura. Esse dado não seria tão surpreendente se contemplasse uma queda d'água convencional, porém estamos falando de uma água vermelha e brilhante cujo contraste se destaca no branco de uma enorme geleira.

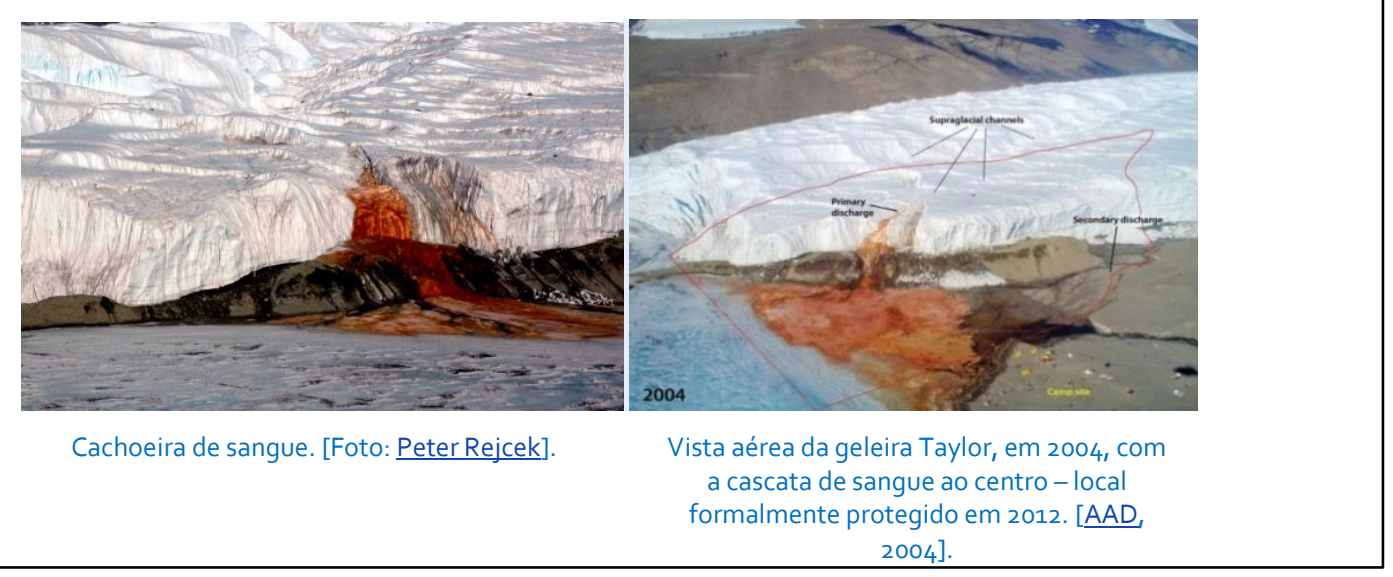

Figura 3. Módulo Gelo - Lagos e Rios

Por meio da figura 3 observamos a utilização da linguagem como um recurso linguístico que vai além do desejo de aproximar o locutor do interlocutor, a articulação enunciativa sugere um convite velado ao influxo da curiosidade expresso na passagem "Você consegue imaginar uma cachoeira no visual antártico? Mas não estamos falando de uma cachoeira comum". Não obstante, o texto não verbal definido pelas imagens oferece uma espécie de suporte ao enunciado como forma de tonificar o anseio pela descoberta de novas informações e nesse intento, dispomos os hiperlinks a fim de facultar caminhos possíveis de conduzir o cursista à autonomia do conhecimento. Em consequência, a dialogicidade faz-se presente e oportuniza a "corporeificação das palavras pelo exemplo" reforçando “a prática do re-dizer em lugar de desdizer” [Freire, 1996, p. 16]. 
V Congresso Brasileiro de Informática na Educação (CBIE 2016)

Anais do XXII Workshop de Informática na Escola (WIE 2016)

A figura 4 denota a utilização da polifonia bakhtiniana a fim de exprimir a recorrência de vozes presentes nos discursos jornalístico, científico e jurídico entrelaçados em um mesmo contexto discursivo. As vozes interligam-se numa teia e abarcam outras vozes no compasso ou descompasso de ressonâncias complementares, concorrentes entre si, ora congruentes, ora desarticuladas [Bakhtin, 2010].

As centenas de baleias capturadas anualmente pelos japoneses indicam que a caça representa muito mais que interesse científico, por esse motivo, em 2013 a Austrália enfrentou o Japão na Corte Internacional de Justiça, maior órgão judicial das Nações Unidas. Confira a reportagem sobre a polêmica japonesa.

\section{Figura 4. Módulo Convergência - As tradições na contramão do cuidado ambiental antártico}

A constituição enunciativa da figura 4 demonstra uma forma de integração da voz que enuncia com a voz discursiva de um outro enunciado. Quando nos valemos desse recurso dialógico, assinalamos a concepção trazida por Fiorin (2008, p. 33) de que "essas formas de absorver o discurso alheio no próprio enunciado são a maneira de tornar visível esse princípio de funcionamento da linguagem comunicacional real”.

O discurso alheio não ocorre apenas na alusão a enunciados de outras cadências discursivas, como podemos notar na figura 5.

O aquecimento global é mais um reflexo do feito humano e na região da Península Antártica, uma das mais afetadas do continente, sua ocorrência é cinco vezes mais rápida do que no restante do planeta. Por esse motivo, os impactos são percebidos de forma heterogênea.

Os gases de origem artificial que se instalam na atmosfera auxiliam na destruição da camada de ozônio. O papel do ozônio é de sorver vigorosamente a radiação do sol na faixa ultravioleta, a qual reproduz efeitos nocivos sobre os seres vivos. Quando a Terra fica exposta à radiação acima de determinadas doses, as consequências podem ser letais para organismos unicelulares de modo a induzir a redução das microalgas e fitoplâncton, base da cadeia alimentar antártica, conforme você vê no módulo Vida.

Figura 5. Módulo Ambiente - Sinais da civilização no continente antártico

O hyperlink Vida conduz ao módulo Vida e projeta o eco de uma voz já posicionada em outro enunciado, assim, na correspondência das vozes percebemos uma entonação harmônica contextual que se esbarra em uma mesma formação discursiva.

A produção de texto dialógico escrito também integra parte da linguagem conferida nas videoaulas cuja impressão compõe uma equivalência enunciativa sustentada pela dialogicidade oriunda do próprio contexto desenvolvido, como apresentamos na figura 6.
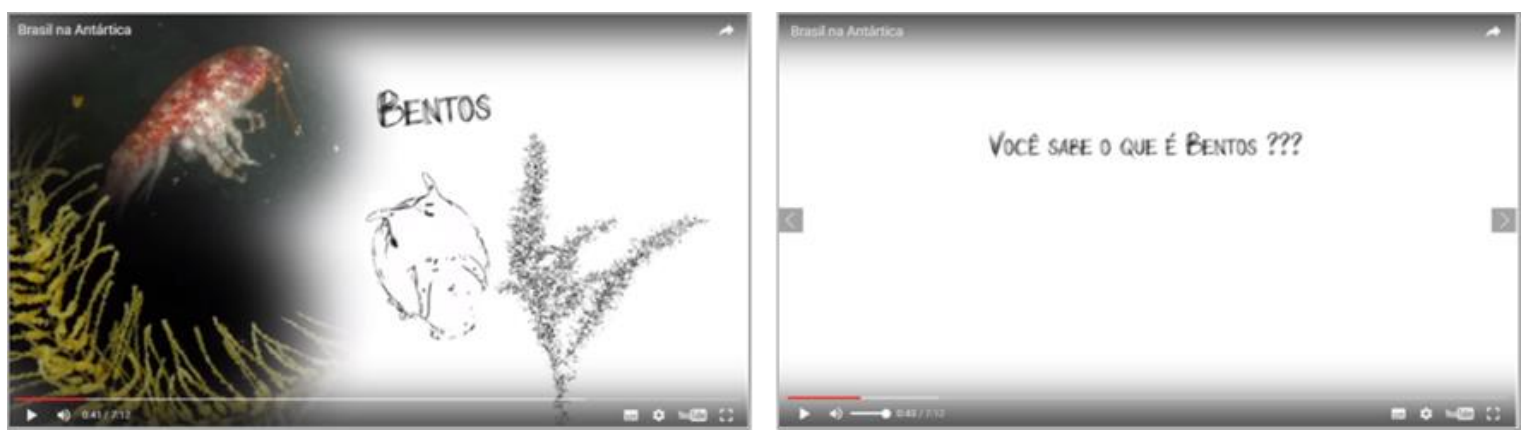

Figura 6. Videoaula - Brasil na Antártica 
A utilização do pronome de tratamento você representa a palavra dialogizada em relação ao sujeito constituído como tu ao passo que alguém é convencionado como eu [Brandão, 2004]. Esse artifício estampa marcas de informalidade na interação locutorinterlocutor e promove empatia ao possibilitar um diálogo mais amigável. Sob essa lógica, demonstramos na figura 7 outro dispositivo linguístico proveniente do dialogismo.

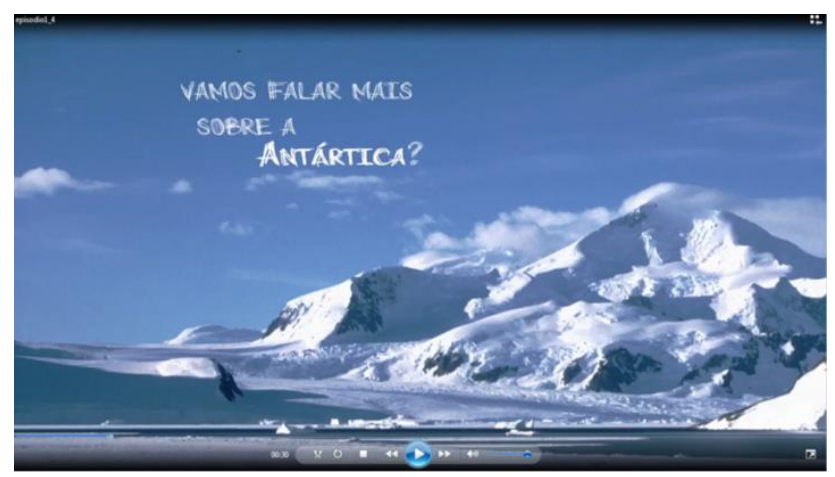

Figura 7. Videoaula - Brasil na Antártica

O emprego da linguagem em primeira pessoa do plural representa um mecanismo linguístico capaz de sinalizar a natureza co-participativa dos atores sociais a partir das projeções de discursos e trazem à memória o alento de uma conversa cujos interesses didáticos estão conectados.

\section{Considerações finais}

A produção de textos dialógicos escritos que compõe o material didático para curso a distância desempenha papel significativo quando o eixo do interesse educacional é promover a reciprocidade dos participantes no processo de ensino-aprendizagem com vistas à construção paulatina e expressiva do conhecimento.

A tessitura discursiva em torno do curso Antártica ou Antártida? Como inserir as Ciências Polares no currículo do Ensino Básico? foi projetada e instituída de modo a prevalecer o funcionamento real da linguagem expresso para além das condições de produção estritamente linguísticas. Assim, como todo enunciado é dialógico, as singularidades enunciativas advindas dessa teoria permitiu-nos trilhar vertentes multifárias de relações significantes.

Os discursos foram confeccionados em diversos tons enunciativos a fim de propiciar a alteridade entre os interlocutores desvelando circunstâncias problematizadoras das quais o convite à reflexão permite conferir abordagens em situações históricas, culturais e ideológicas cuja assimilação abre possibilidades para que o sujeito se perceba diante do mundo.

Por meio da linguagem dialógica pudemos utilizar enunciados promotores de incentivo dos quais os proveitos podem ser refletidos nas interações dinâmicas e nas negociações de sentido difusas na esfera comunicacional.

Em meio a esse panorama, corroboramos as hipóteses formuladas reiterando o dialogismo como instrumento de linguagem profícuo à apreensão dos sentidos e a 
V Congresso Brasileiro de Informática na Educação (CBIE 2016)

Anais do XXII Workshop de Informática na Escola (WIE 2016)

edificação dos significados à medida que transforma o fazer educativo e enaltece a significância da aquisição e valorização do conhecimento no ambiente virtual de aprendizagem.

\section{Referências}

Bakhtin, M. M. (2009) Marxismo e filosofia da linguagem: problemas fundamentais do método sociológico da linguagem. Trad. Michel Lahud e Yara Frateschi Vieira. 13. ed. São Paulo: Hucitec. (Linguagem e Cultura, 3).

. (2010) Problemas da poética de Dostoiévski. Trad. Paulo Bezerra. 5. ed. Rio de Janeiro: Forense Universitária.

. (2011) Estética da criação verbal. Trad. Paulo Bezerra. 6. ed. São Paulo: WMF Martins Fontes.

Brandão, Helena Hathsue Nagamine. (2004) Introdução à análise do discurso. 2. ed. rev. Campinas: Unicamp.

Dotta, Sílvia. (2009) Aprendizagem dialógica em serviços de tutoria pela internet: Estudo de caso de uma tutora em formação em uma disciplina a distância. São Paulo: Feusp. (Tese de doutorado).

- Uso de uma Mídia Social como Ambiente Virtual de Aprendizagem. Anais do

XXII SBIE - XVII WIE, Aracaju, 2011. Disponível em: http://www.brie.org/pub/index.php/sbie/article/view/1623/1388. Acesso em: 27 abr. 2016.

Dotta, Sílvia; Testoni, Elaine A. Contribuições do dialogismo na interação didática assíncrona em mídia social na internet. CBIE-LACLO - Anais do XXI Workshop de Informática na Escola - WIE, Maceió, 2015. Disponível em: http://www.brie.org/pub/index.php/wie/article/view/4979. Acesso em: 30 abr. 2016.

Fiorin, José Luiz.(2008) Introdução ao pensamento de Bakhtin. São Paulo: Ática.

Freire, Paulo. (1987) Pedagogia do oprimido. 17. ed. Rio de Janeiro: Paz e Terra. (O mundo, hoje, v. 21).

(1996) Pedagogia da autonomia: saberes necessários à prática educativa. São Paulo: Paz e Terra. (Coleção Leitura).

Foucault, Michel. (2014) A arqueologia do saber. Trad. Luiz Felipe Baeta Neves. 8. ed. Rio de Janeiro: Forense Universitária. (Campo teórico).

Mello, Elisângela de Fátima Fernandes de; Teixeira, Adriano Canabarro. A interação social descrita por Vigotski e a sua possível ligação com a aprendizagem colaborativa através das tecnologias em rede. Anais do XXII SBIE - XVII WIE, Aracaju, 2011. Disponível em: http://www.br-ie.org/pub/index.php/wie/article/view/1988/1747. Acesso em: 30 abr. 2016.

Orlandi, Eni Puccinelli. (2008) Discurso e texto: formulação e circulação dos sentidos. 3. ed. Campinas: Pontes. 